EDITOR'S NOTE FOR ARTICLES 1 AND 2: Article 1 in this Module is followed by a series of Appendices in Article 2. The Appendices document more fully many of the details in this case study of manualized group treatment, and in so doing they reflect the careful and systematic way in which the various facets of the treatment have been made clear, explicit, and concrete by the authors. Hyperlinks are provided in Article 2 to facilitate navigating within the extensive material provided.

\title{
Identifying and Targeting Idiosyncratic Cognitive Processes in Group Therapy for Social Phobia: The Case of Vumile*
}

\author{
DAVID J.A. EDWARDS ${ }^{\mathrm{a}, \mathrm{b}} \&$ SWETHA KANNAN ${ }^{\mathrm{a}}$
}

\author{
${ }^{a}$ Rhodes University, South Africa \\ ${ }^{\mathrm{b}}$ Correspondence concerning this article should be addressed to David J.A. Edwards, Department of Psychology, \\ Rhodes University, Grahamstown, 6140, South Africa \\ Email: D.Edwards@ru.ac.za \\ * Notes: (1) Based on a paper presented at the Annual Conference of the British Association of Behavioral and \\ Cognitive Psychotherapy held at the University of Warwick in 2002. (2) The research was supported by a grant from \\ the Rhodes University Joint Research Committee. (3) The authors acknowledge the assistance of Professor D.M. \\ Clark in making his treatment manual and rating scales available. (4) An earlier version of this case study was \\ included in Swetha Kannan's Master's thesis presented to Rhodes University, Grahamstown, South Africa (Kannan, \\ 2002). Swetha Kannan is currently living in Canada.
}

\begin{abstract}
"Vumile" was a patient in a cognitive therapy group that was designed for socially phobic African students and based on a therapy model developed by Clark and Wells. The case narrative shows how Vumile constructed a personal model of the factors maintaining his social phobia, and within the group and through homework challenged negative beliefs, reduced selfconsciousness and engaged in a range of previously avoided behaviors. A significant maintaining factor, spontaneous images of women looking at him with pity or mockery, was only identified in the last session. However, Vumile was able to use the skills he had learned to investigate this further and to correct these processes, which were distorting his experience of social interactions with women. Significant gains were made after the end of the formal treatment program and these are reflected in scores at follow-up on several self-report scales measuring anxiety, depression and various aspects of social phobic behavior and cognition.
\end{abstract}

Key words: social phobia; cognitive therapy; group therapy; case-based evaluation; case study 
in Group Therapy for Social Phobia: The Case of Vumile

D.J.A. Edwards \& S. Kannan

Pragmatic Case Studies in Psychotherapy, http://pcsp.libraries.rutgers.edu

Volume 2, Module 1, Article 1, pp. 1-30, 02-17-06 [copyright by authors]

\section{CASE CONTEXT AND METHOD}

\section{A. Rationale for Selecting This Particular Client for Study}

Group therapy has long been seen to offer advantages over individual therapy in the treatment of social phobia. It allows for clients to receive additional social support as well as graded exposure within the group to the kinds of situations social phobics fear, and is potentially more cost-effective (Stangier, Heidenreich, Peitz, Lauterbach, \& Clark, 2003). The case study presented here is one of seven written as part of the evaluation of a group therapy intervention for social phobia adapted by Kannan (2000) from Clark's (1997) manual for individual treatment. Another case study, of a participant who responded particularly rapidly to the intervention, has been reported by Edwards, Henwood, \& Kannan (2003; the case narrative is reproduced, with permission, in Appendix 7 [in Edwards \& Kannan, 2006]). The present paper presents the case of Vumile, the participant who responded least rapidly. In the end he did show substantial improvement, and the comprehensive case narrative provides a means for understanding aspects of the pace of his improvement, and particularly why some of his substantial gains were only made after the program was over.

One of the cornerstones of cognitive therapy is the principle that during the course of treatment, idiosyncratic beliefs, assumptions, behaviors and strategies that are self-defeating need to be identified and specifically targeted. The case of Vumile illustrates the importance of this principle. It also shows how a full understanding of change in psychotherapy cannot be gained by simply evaluating "interventions" applied in a generic manner to diagnoses, but calls for investigation of specific psychological processes within cases as they are activated, and the targeting of these by specific intervention tactics.

\section{B. Clinical Setting In Which the Case Took Place}

The study was carried out at a University Campus in South Africa. Posters displayed on campus (see Appendix 1, in Edwards \& Kannan, 2006) invited students to apply to attend a program for addressing social anxiety. Participants, who were all undergraduate students, were told that the intervention could offer them significant help with their problem and was based on recent research on the most effective current psychological interventions. They also knew that this was a research study and signed consent forms to be studied and written up (see Appendix 3, in Edwards \& Kannan, 2006). They completed self-report scales at regular intervals and video and audio equipment was visible in the therapy room. The researchers tried to create an atmosphere that was as relaxed and informal as possible and seemed to be successful in achieving this. Participants seemed to be encouraged by finding themselves in a group of other students with the same kinds of problem as their own. Because of their common experiences as students, they were easily able to relate to each other and, for the most part, were motivated to work with the various aspects of the program. 
in Group Therapy for Social Phobia: The Case of Vumile

D.J.A. Edwards \& S. Kannan

Pragmatic Case Studies in Psychotherapy, http://pcsp.libraries.rutgers.edu

Volume 2, Module 1, Article 1, pp. 1-30, 02-17-06 [copyright by authors]

\section{Methodological Strategies for Enhancing the Rigor of the Study}

We employed a multiple case study design in which the progress of every participant was portrayed in detail by means of a case narrative. The seven participants (age range 19-21; six black Africans, one white; three females, four males) all met the DSM-IV-TR (American Psychiatric Association, 2000) criteria for social phobia. Each participant understood that data would be gathered systematically for research purposes and that the material would serve as the basis for a set of case studies. They were told that they would benefit from participating in a research study in which they would receive, free of charge, a state-of-the-art intervention for their problem. We, on the other hand, would benefit from the data we collected from them since it would provide the basis for research theses and publications.

Our intervention included all the components described in Clark's (1997) manual. Our approach was also informed by the general principles of contemporary cognitivebehavioral group therapy (White \& Freeman, 2000), and the interventions were presented in ways that took advantage of the group format. Thus, at times, individuals worked in pairs to assist each other in assessing aspects of their anxiety as it manifested in daily situations. At times the group leader used an example from one group member as a basis for a didactic presentation and discussion involving other group members. When roleplays were used to investigate the behavior of one individual, or to allow that individual to experiment with new responses, several group members could be involved by taking different roles. In addition group members were encouraged to support each other outside the group in undertaking behavioral experiments.

The intervention was largely led by the first author, assisted by the second author, a Master's student, who wrote six of the seven case studies, and by an Honours student, who wrote the case study already published (Edwards et al., 2003). The students presented some of the psycho-educational material and participated in the group process. They also attended to the video and audio equipment used to record the sessions, and they collected data by means of research interviews and self-report inventories (see section 1.D).

We took steps to document the therapy process and outcome as comprehensively as possible. The first strategy in this respect was to have three observers (the group leader and the two students) who were all participant-observers of all the sessions and who pooled their observations in a debriefing at every session. Second, all participants were individually interviewed on four occasions. Third, all sessions were video-recorded and these recordings were reviewed repeatedly in writing up the case narratives. Fourth, records were gathered of all written tasks completed as part of the program. Finally, several self-report scales were repeatedly administered to document initial clinical status and progress. Some of these provided qualitative data, but many provided quantitative scores (see Section 1.D for full details).

This complex body of data was systematically organized into displays of manageable size by means of two data reduction strategies. First, repeated measures on the quantitative self- 
report scales were displayed graphically. Second, the various forms of qualitative data were used to write a separate case narrative for each participant. These focused on their experiences as they moved through the program and significant events within and outside the group that reflected progress made or obstacles that were encountered that hindered treatment effectiveness. Narratives were constructed on a session-by-session basis by reviewing all the material available, including self-report forms, worksheets and tape-recordings. Recordings were not fully transcribed, but sections relevant to the experience of each participant were reviewed and selectively transcribed as needed. The narrative was selective and was constructed thematically, with a focus on specific research questions. Care was taken to ensure that accounts of the participant's experience and process were consistent with the material in the various sources of data.

In the first sessions, the focus was on the participants' development of a personal model of their social phobia (for fuller details, see sections 3.B and 4 below). The initial phases of the narrative addressed the extent to which each participant developed a clinically useful model, the extent to which the exercises provided support for this process, and the development of participants' awareness of the specific factors relevant to their social phobia. Later phases of the narrative addressed how the various activities introduced in the program were received by participants, the extent to which they were able to put them to use to develop and implement behavioral experiments and challenge and test cognitive distortions, and the extent to which these processes contributed to clinical change.

This methodology allowed us to conduct an in-depth qualitative investigation into the impact of the intervention program. We could also evaluate the contributions made by each component, as well as obstacles to progress as they played out in each particular case. In these ways, we are able to address research questions about psychotherapy process that cannot be achieved by group comparison designs (Edwards, Dattilio \& Bromley, 2004). A review of all the narratives also provided a means to observe the range of different responses to the various aspects of the program, to evaluate its format and to make recommendations for the future (Barker, Pistrang and Elliott, 1994; Edwards, 1996; Edwards, Dattilio, and Bromley, 2004).

\section{Sources of Data Concerning the Client}

This section describes the types of data we collected about each member of the social phobia group.

\section{$\underline{\text { Interviews }}$}

Four interviews were conducted, as listed below. During these a number of self-report scales were also administered, as described in the next section below.

(i) Screening Interview. In this interview, which lasted about 45 minutes, participants were asked a series of structured questions to establish their motives for applying for treatment, 
to assess whether they met the DSM-IV criteria for social phobia, and to detect whether there might be other significant psychopathology which could contraindicate their participation (including schizoid personality disorder, panic disorder, agoraphobia, body dysmorphic disorder, eating disorders, and substance dependence).

(ii) Pre-Treatment Interview. All applicants met the criteria for social phobia and none met the exclusion criteria, so all proceeded to this next interview, also lasting about 45 minutes. In this interview, the applicants were informed about the general nature of the group intervention and were reassured that, despite their anxiety, they would be able to handle meeting with other students with similar problems and would most likely find this support helpful. The information obtained from this interview and the accompanying self-report scales provided a basis on which the researchers could make an initial case formulation in terms of the Clark and Wells model. (The process of creating a case formulation is described below in section 3 below, Guiding Conception.) Finally, they were given a Self-Report Assessment Form (based on Sank and Shaffer, 1984) to complete at home. This asked for a developmental history; information about current lifestyle academically, socially and with the family; and details of the presenting problem (see Appendix 2, in Edwards \& Kannan, 2006, for more details).

(iii) The Post-Treatment Interview. This interview, lasting 90 minutes, took place within two weeks of the last session. This interview was structured by means of a comprehensive evaluation form (see Appendix 5, in Edwards \& Kannan, 2006) that required participants to reflect on the entire program and summarized the main features of each session. Participants used 7-point scales to rate 40 items about the value of specific components of the program. They were also invited to give an open-ended account of what they had found valuable in the group experience, to voice criticisms or suggestions for improving it, and to assess the extent to which they had benefited from it. This interview was tape-recorded and selectively transcribed.

(iv) The Six-week Follow-up Interview. Lasting 60 minutes, this interview took place about six weeks after the post-treatment interview and was semi-structured. First, clients were asked whether they had maintained their gains or had had experiences of relapse. Second, they were asked for detailed feedback about any behavioral experiments they had conducted since the completion of the program, and whether they had been able to use these to disconfirm negative cognitions. Third, they were asked to voice any additional concerns that had emerged since the end of the program regarding their social anxiety and its effect on their lives. This interview was tape-recorded and selectively transcribed.

\section{$\underline{\text { Self-Report Scales }}$}

Eight of these were administered, as a means of monitoring response to the program, some repeatedly, others only once or twice. They included:

(i) The Social Phobia Rating (SBR) Scale. This was completed at the screening and pretreatment interviews as a means of ensuring that participants displayed the cognitive and 
in Group Therapy for Social Phobia: The Case of Vumile

D.J.A. Edwards \& S. Kannan

Pragmatic Case Studies in Psychotherapy, http://pcsp.libraries.rutgers.edu

Volume 2, Module 1, Article 1, pp. 1-30, 02-17-06 [copyright by authors]

behavioral patterns associated with social phobia. It consists of four, 9-point scales for rating degree of social anxiety, avoidance of social situations, and self-consciousness in social situations as well as checklists of safety behaviors and automatic thoughts typical of social phobics (Wells, 1997). Two scales from Clark (1997) were used twice for the two stages of the "Safety Behaviors Experiment," or "SBE" (see section 3.C below for more details on the SBE).

(ii) The Participant's Self-Rating of the SBE. This scale provides a format for participants to rate their perceptions of the two phases of the SBE.

(iii) The Volunteer's Rating of the SBE. This scale provides a format for the volunteer who took part in the role-play to rate their perceptions of the group member with whom they interacted.

Two widely used standardized scales were administered on 18 occasions (at each interview and each treatment session):

(iv) The Beck Depression Inventory II (BDI-II). This is a 21-item measure of depression based on the symptoms of depression in the DSM-IV (Beck and Steer, 1996).

(v) The Beck Anxiety Inventory (BAI). This a 21-item measure of anxiety symptoms based on the symptoms of panic and generalized anxiety in the DSM-IV (Beck and Steer, 1993).

Three scales from the Clark (1997) manual were administered on 17 occasions (at the pre-treatment interview, at all treatment sessions, and at the two follow-up interviews). These have not been standardized. However, they have strong face validity since they measure the specific aspects of cognition and behavior that the Clark model focuses on and have been used in the development and evaluation of the model by Clark and colleagues (e.g. by Bates and Clark, 1998).

(vi) The Social Cognitions Questionnaire (SCQ). This is a 22-item inventory of cognitions typical of social phobics, which are rated on two scales, frequency and degree of belief (Clark, 1997).

(vii) The Social Behavior Questionnaire (SBQ). This is a 28-item inventory of safety behaviors which respondents rate in terms of frequency.

(viii) The Social Summary Rating (SSR). This consists of five 9-point rating scales that measure social anxiety, social avoidance, self-focused attention, anticipatory anxiety and postevent worrying.

Monitoring of the Intervention and of Responses to It

Monitoring was achieved by the following: 
(i) Tape-recordings. All sessions were video-recorded, and a separate audio recording was also made.

(ii) Worksheets. All worksheets from in-session exercises as well as those generated outside sessions as homework were photocopied and retained.

(iii) A Session Evaluation and Feedback form. This form, which is shown in Appendix 4 (in Edwards \& Kannan, 2006), is widely used in clinical practice and was adapted from Freeman, Pretzer, Fleming, and Simon's (1989) 'Patient's Report on Therapy Session." The form was completed after each session.

\section{E. Confidentiality}

All participants knew that they were participating in a research project and signed a consent form (see Appendix 3, in Edwards \& Kannan, 2006) on which it was stated that interviews and sessions would be tape-recorded and that case narratives would be written as part of the research process. They were informed that names and identifying information would be altered to ensure that they could not be recognized should these narratives be seen by someone known to them. They also agreed to preserve the confidentiality of information about other group members.

The three researchers discussed the case material among themselves but never discussed it in any other context. In writing the case narratives participants were given pseudonyms and specific personal information (e.g., where they lived and courses studied) was omitted. On occasion information was altered (e.g., where a situation on a sports field was discussed, the name of the particular sport would be changed since this had no clinical relevance). In applying this guideline, very little of this kind of information actually needed to be altered or suppressed, and all the case narratives have been in the open shelves of the University Library since mid 2002 without a problem. Throughout the course of the program and interviews, participants appeared to have little concern about the violation of confidentiality and seemed satisfied with the arrangements made by the research team.

\section{THE CLIENT}

"Vumile", a 19 year old black male second year student, met the DSM-IV criteria for social phobia, generalized type. On the BAI, his initial two scores of 46 and 40 indicated severe anxiety symptoms that seemed to have been precipitated by approaching and speaking with the interviewer. His initial two BDI-II scores (both 15) indicated mild to moderate depression. He considered his present life to be "miserable" and felt envious of other students who seemed to live sociable and exciting lives. He could not recall receiving any love or emotional support from his parents, a nurse and a schoolteacher, whom he reported frequently had violent quarrels. Some mornings as a child Vumile would wake up and find chairs broken and holes punched into 
in Group Therapy for Social Phobia: The Case of Vumile

D.J.A. Edwards \& S. Kannan

Pragmatic Case Studies in Psychotherapy, http://pcsp.libraries.rutgers.edu

Volume 2, Module 1, Article 1, pp. 1-30, 02-17-06 [copyright by authors]

the doors. In his early teens he learned that these conflicts were precipitated by his father's affairs with other women.

Both parents used corporal punishment on him unpredictably and for minor offences (on one occasion he was beaten for losing 50 cents). Vumile would be hit by a belt, including the metal buckle, and with metal chains. On some occasions blood was drawn. Vumile used the metaphor of a boss and a slave to describe his relationship with his father. His mother was inconsistent as she would unpredictably behave in a critical and cruel manner. He had two younger brothers with whom he reported feeling no meaningful bond.

Vumile spent most of his time studying, playing tennis and watching TV. He hardly ever attended a social event. He had a few friends, but he experienced them as critical because they kept commenting on how quiet and withdrawn he was and described him as "antisocial." He came across as quiet and timid and reported that others found his voice so quiet that they always responded with "Huh?" As a result he felt even more afraid to speak up. He had never dated a girl. He was keen to try the therapy program because he recognized in himself all the symptoms described in the posters inviting people to participate. In the screening interview he seemed afraid to answer questions. Although he appeared to be resigned to this lonely way of life, he genuinely hoped that the program might bring about change. He said,

I want to be able to go out and have fun without worrying about what others are thinking about me. ... I really want to know how to go about approaching a girl I like without freezing up and saying something stupid because I'm so nervous.

On his Self-Report Assessment Form (Appendix 2, in Edwards \& Kannan, 2006), he wrote that he wanted "to feel adequate because this would help me have faith in my dreams."

\section{GUIDING CONCEPTION WITH RESEARCH AND CLINICAL EXPERIENCE SUPPORT}

\section{A. Clark and Wells' Assessment and Treatment Model}

Even before social phobia appeared in the DSM-III as a distinct diagnostic category (American Psychiatric Association, 1980), psychologists had been using a range of interventions to address social anxiety. These included applied relaxation, systematic desensitization, social skills training, exposure based interventions, and various forms of cognitive restructuring (Heimberg \& Juster, 1995). Many of these had been employed in group therapy, a setting which allowed for participants to learn from each other, to help each other problem-solve around specific situations, and to work together on role-playing more assertive behavior (e.g. Lange and Jakubowski, 1976).

Since then, there has been a progressive refinement of our understanding of the cognitive, emotional and behavioral processes that underlie social phobia, giving rise to information 
in Group Therapy for Social Phobia: The Case of Vumile

D.J.A. Edwards \& S. Kannan

Pragmatic Case Studies in Psychotherapy, http://pcsp.libraries.rutgers.edu

Volume 2, Module 1, Article 1, pp. 1-30, 02-17-06 [copyright by authors]

processing models that can be used as the basis for the streamlining of therapeutic interventions (Clark and Wells, 1995; Rapee and Heimberg, 1997; Wells, 1997; Wells \& Clark, 1997; Wilson \& Rapee, 2003). One of these is Clark and Wells' (1995) approach that serves as the basis for the Cognitive Therapy for Social Phobia (CTSP) program, a detailed assessment and treatment model that has been manualized by Clark (1997).

At the heart of Clark and Wells' theory is the idea that excessive focus on negative beliefs about and images of self causes social phobics to experience heightened selfconsciousness, which interferes with the spontaneity that is the hallmark of satisfying social interaction. Attention consumed by self-focus is not available to direct and organize the kind of perception and responsiveness needed for effective social performance. The theory is parsimonious in that it suggests that the therapeutic task is to replace this self-consciousness with an experience of natural and spontaneous engagement with others.

The theory identifies a range of cognitive and behavioral factors that contribute to the maintenance of social phobia. One of these is what Fenigstein, Schneier, and Buss (1975, p. 523) called "public self-consciousness," which they defined as "awareness of self as social object." This excessive concern about how one appears to others gives rise to anxiety whenever individuals judge that their appearance falls short of some internal standard (Buss, 1980). This may result from images of self as inadequate or ineffective (Hackmann, Clark, \& McManus, 2000) and be exacerbated by a range of exaggerated and distorted negative beliefs and assumptions.

The resulting anxiety symptoms may be mistakenly interpreted as further signs of inadequacy and be believed to be far more visible to others than they in fact are. Individuals attempt to cope with the anxiety by mobilizing a set of safety behaviors. As an example, the safety behaviors Vumile used are summarized in Box 4 of Figure 1. Their function is to reduce anxiety and self-consciousness by (a) concealing anxiety symptoms from others (e.g., by holding on to a chair to prevent shaking and wearing long sleeves to prevent perspiration being visible); (b) making it more difficult for others to detect one's inadequacy (e.g., by avoiding eye-contact or speaking rapidly so that the time during which one is evaluated will be shorter); or (c) warding off humiliating events such as speech pauses (e.g., by mentally planning well in advance what one is going to say). These strategies are self-defeating since, rather than helping to manage the situation, they consume attention and disrupt spontaneity. Furthermore, they may result in others experiencing the individual as awkward or even arrogant and responding by showing discomfort or withdrawal. These responses from others are frequently interpreted as evidence that one is undesirable or inadequate.

Assessment is designed to provide an understanding first of the phenomenology of the individual's self-focus, and second, of the factors that contribute to activating and maintaining the self-focus. Clark and Wells' assessment model is summarized in the 5-box format of Figure 1 using data from Vumile's case (note that tables and figures are presented below, after the References). 
As can be seen, Box 1 lists the affected situations. In cases of generalized social phobia, such as that of Vumile, there can be a large number of these. Box 2 includes specific beliefs and assumptions that render the individual vulnerable to social phobia. These include assumptions about the importance of physical appearance in making a good impression, beliefs about one's own inadequacy or defectiveness, and expectations of being humiliated. These cognitions mobilize anxiety in social situations that manifests itself in specific anxiety symptoms, listed in Box 5. These in turn heighten the salience of the cognitions in Box 2. They also serve to trigger self-focused attention, summarized in Box 3, the experience of intense self-consciousness. Attention is largely focused on thoughts or images of oneself appearing to others in an extremely negative light so as to attract ridicule or rejection. Attention is thus diverted away from the practical demands of the situation, and from attending to the exercise of normal social skills. Box 4 lists the associated safety behaviors.

The objective of Clark and Wells' CTSP treatment program is to break up selfconsciousness and allow clients to discover and develop a natural and spontaneous style of interaction. The program includes psycho-education, strategies for reducing self-focus, identification and challenging of cognitive distortions, the dropping of safety behaviors, and the planning and execution of a systematic series of behavioral experiments to test and challenge dysfunctional beliefs that interfere with spontaneity. These interventions are not ends in themselves, but they are valuable in so far as they contribute to the overall goal of developing naturalness and spontaneity.

\section{B. Empirical Basis of the Theory and Efficacy Research on the Intervention}

Clark and Wells' approach is informed by a number of experimental studies, but is also based on "extensive clinical work" (Wells \& Clark, 1997, p. 9). That is, there is an implicit database of case studies that have served as the empirical foundation for the model. Most are unpublished, but some are presented as brief case vignettes by Clark and Wells (1995), Clark (1997), and Wells (1997). Bates and Clark (1998) report a detailed case study, and Wells and Papageorgiou (2001) describe a case series in which an abbreviated form of the intervention was used.

The efficacy of individual CTSP has been evaluated in a randomized control trial by Clark, Ehlers, McManus, Hackmann, Fennell, et al. (2003), which was still unpublished when we conducted our study. In the Clark et al. study, individual CTSP was statistically superior to two other treatments, self-exposure with either Fluoxetine or placebo. Treatment gains were well maintained a year later. An effect size of 2.14 for cognitive therapy was substantially higher than those obtained in previous trials of other forms of cognitive-behavioral therapy (Clark et al., 2003).

In a German randomized controlled trial involving over 70 patients, also in progress while we were conducting our study, Stangier et al. (2003) compared a group version of CTSP with individual CTSP. Though statistically effective, group CTSP was inferior to individual 
CTSP. (Of note was the fact that effect sizes for individual CTSP were considerably lower than those obtained by Clark et al. [2003]). Stangier et al. (2003) hypothesized that in their group format therapists may not have been able to "devote as much attention to identifying idiosyncratic behavior, strategies and beliefs and using this information to maximise the cognitive change achieved by the main treatment components" (pp. 1002-1003).

\section{Translating the Guiding Conception into a Manualized Group Therapy Intervention}

Our manual for the group program (see Appendix 6, in Edwards \& Kannan, 2006) is effectively a supplement to Clark's (1997) manual for individual treatment. The task of adaptation was relatively straightforward since we employed most of Clark's specific interventions and psycho-educational materials. The program consisted of (a) 13 group sessions of 11/2-2 hours, and (b) a 2-hour, individual, Safety Behaviors Experiment (SBE) and video feedback session. The content of the intervention is summarized only briefly here. More detail will be found in the case narrative (sections 4/5 and 6 below) and in Appendix 6 (in Edwards \& Kannan, 2006).

\section{$\underline{\text { Sessions 1-5 }}$}

There were two aims in these sessions: (1) to build group cohesiveness, and (2) to guide each participant in making an analysis of his or her socially phobic behavior, as summarized in the type of model illustrated in Figure 1 for Vumille (also see Appendix 6, session 1, in Edwards \& Kannan, 2006). Developing each individual's model of their socially phobic behavior was achieved by psycho-education; by group exercises in pairs in which group members helped each other to identify examples from their own experience; by guidance from the group leaders, who used examples from the participants' experience to illustrate aspects of the process; and by a series of homework tasks. We devoted much more time to this than in Clark's CTSP, where the model was generated in the first two sessions; or in the Stangier et al. (2003) program, where it was generated in an initial individual session. After the first five sessions, a seven-week break followed due to university examinations and a vacation.

\section{$\underline{\text { Safety Behaviors Experiment (SBE) and Video Feedback }}$}

For these sessions, conducted individually between sessions 6 and 8, we recruited one or more people to take part in a role-play situation chosen by the client. There were two, short roleplays of about five minutes each. In the first, clients were instructed to employ their usual safety behaviors; and in the second, they were asked to drop them as far as possible. After the two roleplays, the therapist gave the client verbal feedback about how he or she was perceived by the other role-player. Then therapist and client watched a video-recording of the two role-plays and discussed it in a manner designed to help the client test the accuracy of negative beliefs and predictions. 


\section{$\underline{\text { Sessions 6-13 }}$}

There were two aims. First, participants were encouraged to enter anxiety provoking situations in a graded manner and to act spontaneously without safety behaviors. These activities were structured as behavioral experiments in which negative predictions were written down beforehand on a Behavioral Experiment Record Sheet (see Appendix 6, session 7, in Edwards \& Kannan, 2006), and the actual outcome was recorded so that the accuracy of the predictions could be assessed.

Second, in parallel with this, clients were taught the following: (a) to recognize and challenge negative cognitions in the form of automatic thoughts, underlying assumptions and core beliefs; (b) to monitor and eliminate the "post-mortem" (i.e., worrying about a social event afterwards), since this sort of worrying tends to reinforce rather than accurately test distorted negative beliefs; (c) to build a positive (and accurate) self-image; and (d) to make a maintenance plan that included relapse prevention strategies. Such a plan was considered particularly important since setbacks are common after any new cognitive-behavioral retraining, and these can be prevented from turning into relapses if the new skills that have been learned can be mobilized and reapplied.

\section{4-5. ASSESSMENT AND FORMULATION}

The assessment and case formulation was undertaken as a collaborative activity between the group leaders and Vumile across the first five sessions. A series of structured activities guided him through the collection of the data that is summarized in Figure 1. These activities included a series of exercises in pairs designed to focus on one box of Figure 1 at a time. One member interviewed the other asking him/her about the behavior relevant to the particular box and taking notes. Then the roles were reversed. Vumile himself also recorded thoughts, feelings and behaviors in critical incidents between sessions. He displayed anxiety and avoidant behavior in a wide range of social contexts (Figure 1, Box 1). Where possible, he avoided these situations, hardly ever went out socially, and had never initiated a conversation with a girl.

Figure 1, Box 2 shows some of his negative beliefs about himself and others in social interaction, e.g., "They'll laugh at me." His avoidant behavior regularly resulted in his thinking "I'm useless." He believed that people who interacted with him would find him uninteresting, boring, antisocial, and inadequate. Entering a social situation he would predict, "I will make a bad impression. . . . I will not succeed." If he remained passive, he expected to be branded "antisocial," but if he spoke he expected that he would not know what to say, would say something nonsensical, or would sound foolish because of his strange voice. If people addressed him, he believed this was either because they took pity on him or wanted to make fun of him. One evening, in residence, when several peers were planning to go out, he thought, "If they noticed me and included me, their aim would have been to laugh at me and torture me further." If there was a pause in the conversation, he expected that the other would think, or actually say, "You're such a loser, and so boring." When making a compulsory speech in class, he thought, 
"I'll make a fool of myself, . . I'll get my words mixed up." When the class applauded the speech, he believed that they were doing this out of pity.

Figure 1, Box 3 summarizes important features of his experience of negative self-focus. Vumile saw himself as small, puny, visibly shaking with anxiety, and with a strange, inaudible voice; and he believed he looked and sounded ridiculous. All this gave rise to severe anxiety symptoms (Figure 1, Box 5). If a girl struck up a conversation with him, he would not be able to concentrate and would freeze up. For homework he tried to initiate a conversation with a girl in the computer laboratory, but he felt so faint that he aborted the attempt. His safety behaviors (Figure 1, Box 4) exacerbated the problem. He hung around on the edge of groups hoping not to be noticed. When in a group, he averted his gaze so as not to see who was laughing at him. When someone engaged him in interaction, he avoided eye-contact and looked past the person's shoulder. These behaviors contributed to his peers mocking him and calling him "antisocial." He kept very still to prevent others seeing him shaking, and he wore full clothes to conceal perspiration. When someone else initiated interaction, he censored spontaneous thoughts and focused on covertly planning sentences. He tried to keep smiling and asked a lot of questions in order to appear interesting. However, he was unable to concentrate on the answers as he was busy planning the next question. This, of course prevented any spontaneity developing.

Vumile wrote his own analysis as a homework exercise. This was not as comprehensive as Figure 1, which was reconstructed from the material brought to light during sessions and homework. Nevertheless, his own written analysis indicated that he was growing in awareness of how these behaviors and beliefs interacted to maintain his social phobia, and he was able to talk about aspects of it to the whole group. However, while several group members were already applying cognitive restructuring to their phobic situations, Vumile showed little progress in this regard.

\section{COURSE OF THERAPY}

\section{A. Sessions 1-5: Building Group Cohesiveness and Creating a Summarized Model of Each Member's Socially Phobic Behaviors}

The first five sessions served to build group cohesion, since the group leader ensured that all members participated and shared specific problematic experiences by introducing examples from the homework sheets of each member into the group. This was done respectfully. The group leader asked the participant's permission before disclosing information to the others. In session 5, Vumile shared the event referred to above that had taken place on Saturday evening in the residence common room. A group of peers were making plans for the evening, and Vumile realized that, unless he joined in, he would wind up alone. He said nothing, however, fearing that he would not make a good impression. He expected to appear strange, to say something that would come out wrong, and/or to speak with an inaudible voice and be laughed at. Later, he thought, "If they had noticed me and included me, their aim would have been to laugh at me and 
torture me further." The sharing of this episode and the associated vulnerability demonstrates the trust he felt that the group members would be able to empathize with and support him.

The exercises in pairs gave the group members the experience of working closely together and interacting individually with all of the others. Each had the experience of being assisted by another and assisting another, as each member took two roles: (a) that of interviewer (asking structured questions to help the other identify specific thoughts, feelings or behaviors); and (b) that of interviewee (responding to structured questions posed by the partner). Group members engaged in these exercises respectfully and thoughtfully. As the sessions progressed, an environment was built up of acceptance and mutual support because all participants were engaged in a common purpose, to identify and describe the various aspects of their socially phobic behavior so that later they could work to change it.

\section{B. The Vacation Break}

The vacation break after session 5 was not deliberately planned. Indeed, we were concerned that it might increase the risk of participants dropping out. Because of the pervasiveness of Vumile's negative thinking and his frequently expressed pessimism that he would not be able to change, we were concerned he might lose momentum and drop out. In fact, two other participants (a black male and a black female) did drop out, claiming that the program was too time-consuming. However, Vumile did return, motivated to continue and keen to tell the group about experiments undertaken during the vacation. He had gotten the message that change depended on experimenting with new behavior, and he had actively gone out to socialize on several occasions and had some positive experiences. Several people had treated him warmly (including two girls who were friends of his cousins), but he had interpreted this as evidence that they pitied him.

In addition to inviting members to reconnect with each other and share developments during the vacation, we used the sixth session to help each participant devise an appropriate situation to role-play in the Safety Behaviors Experiment (SBE) experiences that we would conduct in individual sessions over the next three weeks. We explained that this was the end of the assessment phase. From now on the group members would be given a series of active exercises that would provide the means to overcome their self-consciousness and avoidance.

\section{SBE Exercise and Video Feedback}

\section{The First Roleplay}

Vumile's SBE session took place between the $6^{\text {th }}$ and $7^{\text {th }}$ group sessions. In the SBE session, Vumile role-played approaching a young woman at a party. He offered to get her a drink, sat down with her, and then began to converse. The young woman was played by a student volunteer from a psychology class who was previously unknown to Vumile or any of the research team. She was recruited by the researchers and was told she was taking part in a "social 
skills research study." In the first role-play Vumile was instructed to behave as he normally would, with all his safety behaviors. When asked to predict what would happen, he said he believed the volunteer would notice his nervousness and would find him uninteresting and antisocial because he would not know what to say. He did indeed display his habitual safety behaviors. He made an effort to speak loudly and clearly, asked a lot of questions, and kept still and gripped his glass tightly to control his shaking. He had also worn full clothes to conceal perspiration.

After the role-play (which lasted about 8 minutes), he was convinced that she had found him boring. He had run out of questions to ask her and was sure she would have noticed his uneasiness and anxiety. He had not heard any of her answers to his questions and concluded that she must have found him incoherent. A pause of a few seconds that had seemed to have lasted several minutes precipitated further thoughts that she would have found him uninteresting. The volunteer had a rather different experience. She found Vumile friendly and would have liked to have asked him more about himself. Although she noticed that he seemed uncomfortable in his clothes and in the way he was seated (she commented later that he "looked like a statue"), she did not perceive him as nearly as anxious or self-conscious as Vumile did himself. Table 1 provides a quantitative picture of the discrepancy between Vumile's and the volunteer's experience of their interaction.

\section{The Second Roleplay}

In the second role-play Vumile successfully dropped his safety behaviors, asked fewer questions, and gave the girl more of a chance to speak. He rated his performance 6 as compared to 3 on first role-play (Table 1). Although he felt vulnerable without his safety behaviors, he had enjoyed the conversation much more. Towards the end, he had suddenly panicked and started asking questions in a disorganized way. The girl responded by laughing and saying "Huh?," and he felt like a fool and believed he had made a bad impression. The volunteer's experience was that Vumile was much less anxious and self-conscious than before and had good interactions skills, and seemed much more comfortable in the way he sat and moved his hands. She noticed that he became more self-conscious towards the end when he suddenly started asking "silly, trivial questions." Although not instructed to do so, she had decided to be a little less friendly during this role-play, and felt Vumile had handled this extra pressure well. She mentioned that she would not mind meeting him again in a less formal situation.

\section{Video Review}

Next, Vumile watched video replays of his role-plays. Vumile was first asked what he expected. He had never seen himself on video before and expected to appear nervous and shaky with a strange voice. As they watched, the group leader stopped the tape at various places, asked for Vumile's observations, focused on specific aspects of the interaction, and initiated Socratic dialogue about aspects of the observations. There were several positive gains. Vumile spontaneously observed that as the volunteer was in fact shorter than him, he did not in fact look 
"small and puny." Furthermore, the shaking he had experienced was not visible, and he did not even notice the pause that had seemed interminable at the time. He could see that his safety behaviors were counterproductive. His constant smile and efforts to keep still made him look uncomfortable. "No wonder people laugh at me," he observed, "I look ridiculous." He could see that his questions did not relate to the volunteer's responses to his previous questions. Despite all this, he had a far less negative impression of himself than that portrayed in his usual negative self-focus, and he thought the volunteer's ratings of him were realistic.

Watching the second role-play, Vumile could see that he appeared natural and spontaneous (except at the end when he became flustered by the pause) and that he sounded better when he did not deliberately try to sound loud and clear. The effect of his making eyecontact and not straining to keep still was that he looked like "a real stud." He enjoyed watching himself interacting with such ease and could hardly believe he had had such a spontaneous conversation with a girl. The fact that she had deliberately tried to be less friendly in the second role-play encouraged him even further. He thought her ratings accurately reflected what he saw. On the feedback questionnaire he rated this SBE session as much more valuable than the previous group sessions. The experience had challenged the basis of his social phobic cognitive system.

\section{Sessions 7-13: Practicing Alternative Behaviors in Social "Experiments"}

When Vumile shared his SBE experience in session 7, he dismissed it as "a once in a lifetime experience" that would not have happened "at a real party." "With other guys around, she would never have sat with me or given me the time of day," he claimed. In response, Tabelo, who had also had a positive SBE experience that he did believe would generalize to real situations, invited Vumile to accompany him to a night club and offered to help him test this prediction in a behavioral experiment.

At session 8, Vumile described what happened. Tabelo had been able to initiate conversations with girls, but Vumile had not. He identified a girl he wanted to approach, but was afraid he would not know what to say, took no action, and stayed alone and isolated. He asked himself, "What do other guys have that I don't?" To address this, the facilitators set up a roleplay in which female group members gave him feedback about their responses to his behavior. They told him, after several attempts and some coaching, that he was coming across as natural and confident about himself. However, Vumile dismissed the feedback on the grounds that they pitied him and were trying to be kind. This belief kept on coming up. Alternative explanations and evidence against it failed to make any impact. In the present situation there was plenty of contradictory evidence. Group members had been caring but had given him plenty of tough feedback when he behaved timidly in the role-play. It turned out that we were missing something. After the program was over, we would look back and see why this belief was so persistent, but at this stage it was getting away from us because we had not identified a specific cognitive process maintaining the problem! 
In session 10, Vumile reported that two girls had asked for help in the computer lab. He turned this into a behavioral experiment and used what he had learned. After he had helped them for about an hour, one of them who had noticed him in the residence suggested they walk back together. The fact that she had noticed him took him by surprise. He became anxious about what to say, but instructed himself to "forget you ever owned safety behaviors, just go with the flow." He was able to be so spontaneous and humorous that the girl "laughed her head off all the way home" and suggested that they meet up again in the future. He was able to evaluate the evidence from this experience realistically. It was obvious she had not spoken out of pity either when asking for help or when suggesting they walk together. He recognized that he had been able to converse even more spontaneously and free of anxiety than in the second role-play and that she had really enjoyed his company. He began to believe that he could succeed in interacting comfortably with females.

Session 13 was the last. Vumile had decided he would do something that would enable him to "leave the group with a bang" and had gone alone to a night club. On his behavioral experiment record sheet (see Appendix 6, materials for session 7, in Edwards \& Kannan, 2006), he predicted that he would "look like a lost sheep with nobody to talk to and would not belong" and associated this with a $60 \%$ probability. However the prediction proved wrong: "Everybody treated me like a regular. People were greeting me, some came over to talk to me, some wanted me to join in and dance with them." He rated the probability of this happening again as $99 \%$ and concluded, "The thought of not being like everybody else is the most wrong thought I have ever had." Vumile was clearly making significant progress. However, he had not yet initiated contact with a girl and had had no further contact with the girl he had met in the computer lab.

Lindiwe, a female group member, provided a catalyst for the important next step. Several people from the residence had commented to her about the positive changes in Vumile's "attitude," and she told him that he had a few secret admirers. This information re-evoked Vumile's belief that girls only interacted with him out of pity. "Why do girls continue to look at me in the same way as they did before?" he remarked. When the group leader asked further exploratory questions, it became clear that Vumile's belief that girls looked at him in a pitying way was being maintained not by perceptual data from actual situations, but by internalized images, perhaps based on a few significant memories. He was experiencing pitying looks from girls, even though this was not actually happening. This was reinforced by the safety behavior of avoiding looking at girls' faces to see their true expressions. In conversation, he would normally look past her shoulder rather than at her face. We encouraged him to continue with behavioral experiments that tested these predictions, but we were concerned that this insight had come too late as the program was now over.

\section{E. Follow-up Interviews}

What happened over the next few weeks took the research team by surprise. We had underestimated Vumile's persistence and motivation as well as the thoroughness with which he had learned and understood the cognitive model! Three weeks later, at the debriefing interview 
(with the second author, who is female), he reported that he had been conducting systematic experiments in which he observed girls' facial expressions in a variety of contexts, including when they were looking at him and when they were looking at other males. The exercise was very anxiety-provoking, but he was motivated by what had happened in the group, by Lindiwe's feedback, and by what he had learned about the value of behavioral experiments.

In the past, he realized, he had never really looked at girls' faces at all. He expected expressions that indicated mockery or gave the message, "How dare you look at me, you strange person!" However, his naturalistic observations provided no evidence for this and profoundly altered his belief system. Girls looked at him in the same way as they looked at other males. This contradicted his belief that there was something peculiar about himself. Girls were generally friendly and smiled at males who made and maintained eye-contact with them, but would laugh at and comment about males who avoided noticing them. He concluded that this was because the girls felt embarrassed and covered this up by trying to humiliate these males. Vumile saw admiration and attraction in some girls' expressions. Some seemed to be "calling me with their eyes."

At the final follow-up interview six weeks later, Vumile reported that he had continued to conduct behavioral experiments. He had approached a girl he was not specially attracted to, in a cafeteria,. He had felt his heart pounding and felt himself shaking, but had not let this distract him. He struck up and sustained a pleasant conversation and felt very positive about the experience. He had also approached a girl he was attracted to. Again there was considerable anxiety, but he instructed himself: "Drop all safety behaviors, keep attentional focus on the conversation, let the conversation flow. If it doesn't flow, walk away confidently and try again some other time." This conversation was the beginning of a friendship that had already been sustained for two weeks and there was clearly a growing mutual attraction. Vumile knew the next step was to "propose a relationship," and he was planning to take her out to a restaurant and do this in the near future.

\section{THERAPY MONITORING: GRAPHICAL PRESENTATION OF REPEATED MEASURES}

Figures 2 through 6 provide graphical displays of the repeated measures on the Beck Depression Inventory (BDI-II), the Beck Anxiety inventory (BAI), the Social Cognitions Frequency (SCF), the Social Summary Rating (SSR), and the Safety Behaviour Questionnaire (SBQ). These data complement the case narrative and reveal interesting relationships between the process of Vumile's response to the group and his mood, emotions and beliefs. Scores were collected on two occasions prior to the first session, at each group session (he missed session 11 due to illness), at the SBE, and during the two follow-up interviews. Interpretations are based partly on the content of the case narrative and partly on remarks by Vumile himself at the final interview. 
The drop in scores between the last session and the two follow-up interviews is a particularly noticeable feature of all the graphs. This reflects the impact of Vumile's systematic observations of women's facial expressions and the overwhelming evidence this provided that they were not invariably looking at him mockingly. Although the earlier experiences in the therapy group enabled him to make significant gains and laid the foundation on which this observational experiment could build, it was only through conducting these observations and attending to the evidence they provided that he was able to find a consistent alternative experience of being in relationship to women.

His BDI-II scores (Figure 2) show that his mild depression remained unchanged during the first phase; the drop at the time of the Safety Behaviors Experiment (SBE) seemed to reflect his hope that he could change; and he became more depressed over the next few weeks as he saw other group members making progress while he did not seem to be. The marked shift towards the end coincided with his discovery that he could interact spontaneously and freely with people.

Figure 3 displays his BAI scores. The high anxiety at the start was evoked by the initial contact with the researchers and the group. The drop in anxiety that occurred during the next few weeks was probably due to his becoming comfortable with the group and to returning, to some extent, to his normal avoidant behavior. His anxiety was raised by the exposure involved in the Safety Behaviors Experiment and the subsequent behavioral experiments. However, he never again reported the severe anxiety that occurred at the start.

Figure 4 shows the frequency scores of the Social Cognitions Questionnaire. This is scored for degree of belief and frequency. Vumile's scores on both of these were the highest in the group. The belief scores, not shown here, steadily declined, but there was a sudden elevation at the end. Vumile explained that he realized that although they no longer bothered him much, they were still believable in the sense that the negative outcomes were still possible. This elevation seemed therefore to be anomalous. His frequency scores remained high throughout, peaked as the exposure work began and decreased dramatically after the program was over. The same pattern is reflected in the Social Summary Ratings shown in Figure 5, which include anticipatory anxiety, self-focus and post-mortem activity.

Figure 6 displays the Social Behavior Questionnaire, which measures safety behaviors. It can be seen that although he learned a great deal about safety behaviors as the program progressed and could drop them at times in response to the group exercises and some homework assignments, he only felt safe enough to drop them in a pervasive way once he realized that women were not constantly looking at him with ridicule. It is not, therefore, enough to have insight into the self-defeating nature of these behaviors. In Vumile's case they were mobilized automatically in response to the threat created by internally generated images of people ridiculing him that he mistook for reality, and only dissipated once these images had been addressed. 


\section{CONCLUDING EVALUATION OF THE THERAPY'S PROCESS AND OUTCOME}

\section{A. Vumile's Progress: A Comparison with Other Cases}

In this section, some cross-case comparisons will be drawn with the cases of Tabelo, Mary, Lindiwe and Sam, from our study, and with Lynn, treated with individual CTSP by Bates and Clark (1998). Apart from the two drop-outs, Vumile was the participant who responded most slowly to our intervention and much of his progress occurred after the program was over. By contrast, Tabelo, who responded most rapidly, made considerable progress even before the SBE took place (Edwards et al., 2003; see Appendix 7 for the case narrative, in Edwards \& Kannan, 2006). Although Vumile's anxiety as measured by the BAI declined between the initial assessment and the last session, his score of 19 at the end was higher than most of the others whose scores ranged from 0-11. The exception was Sam (also 19). This accords with the conclusion that Vumile's social phobia had not been fully addressed by the end of session 13 in contrast to some of the others. However, by the first follow-up, Vumile's score of 5 was among the lowest, lower than that of Lynn (13), Sam (10), and Lindiwe (9), and was maintained at the second follow-up. This is evidence that significant gains were made by Vumile during the follow-up period.

On the BDI-II, both Lynn and Tabelo were somewhat more depressed than Vumile before treatment began. However, Tabelo's depressed mood dropped sharply as soon as the program began and remained in the normal range thereafter. Lynn's depression dropped to normal by the end of the treatment (no information is reported on a weekly basis); there was a brief relapse 3 months later, not related to social anxiety; and she was not depressed at 6 months (Bates and Clark, 1998). Although Vumile's depression increased during the second half of the program, he was in the normal range by the end, and only Lindiwe's score (also normal) was higher than his. At final follow-up, in all cases, including Vumile's, BDI-II scores were 7 or below.

SBQ scores, which reflect safety behaviors, were all between 40 and 50 pre-treatment. By the end, only Lynn (24) and Tabelo (15) and to a lesser extent Sam (29) showed a clear drop. Vumile showed a sudden drop at the first follow-up which was sustained so that at second follow-up his SBQ of 14 was the lowest. Despite making progress on other measures, Sam (26), Mary (31), and Lindiwe (44) all had relatively high SBQ's at final follow-up. A possible hypothesis for future research is that failure to fully eliminate safety behaviors may render individuals vulnerable to relapse. Although we have no long term data on Vumile, we hypothesize that his experience of interacting spontaneously without safety behaviors would protect against relapse.

There was a marked contrast between Tabelo and Vumile in the pattern of change on the SSR measure of anticipatory anxiety, self-focus and post-mortem activity. They both began at 30. Tabelo's score had dropped to 15 before the Safety Behaviors Experiment, and it dropped 
steadily to 3 by the end of the treatment, where it remained. As can be seen from Figure 5, Vumile's score only began to drop in session 10, and it was still at 21 at the end of treatment. However, he was down to 9 by the final follow-up, at the same level as all the others. These contrasting rates of response are a good reflection of the different paces of qualitative change documented in the two case narratives.

Bates and Clark (2000) found a marked change in Lynn's SCQ (both frequency and belief) scores, which measure cognitions typical of social phobics, immediately after the Safety Behaviors Experiment. However, this was not a clear trend in the present study. Like Lynn, Mary's SCQ also dropped at this time, as did her BAI and SSR (her depression had already dropped by her return from vacation). Tabelo, on the other hand, showed a clear drop on the SBQ right after the SBE, although he had already evidenced marked change on the BAI, BDI-II, SCQ, and SSR several weeks earlier, having responded positively to the assessment and psychoeducational phase. For Lindiwe, Vumile, and Sam, there was no detectable impact of the SBE, despite the fact that they all reported that it was a valuable experience.

These observations highlight how complex and idiosyncratic are responses to specific components of the intervention, and how diverse are responses across the various measures employed. Each measure taps a different aspect of social phobic cognition and behavior, and scores on the various measures do not necessarily rise and fall together. These patterns also suggest that recovery from social phobia depends on addressing a wide range of maintaining factors across a broad front until the cycles that keep the avoidance and anxiety in place can eventually be broken and participants can find for themselves the experience of spontaneity and natural social engagement, and having found it, return to it regularly.

\section{B. Lessons from Vumile's Case}

The narrative provides evidence that it was the treatment that was responsible for Vumile's marked improvement and that his gains cannot be attributed to "spontaneous recovery." Although we did not collect a long baseline before the initiation of treatment, the first few weeks of treatment were, in effect, a baseline in that he did not show any marked improvement on most measures. There is sufficient concordance between the qualitative aspects of the case narrative and the graphs of the self-report scores to provide strong evidence for a causal relationship between his improvement and the activities and changes in his life that he undertook in response to the treatment. In CTSP, clients are not passive recipients of treatment, but active participants. Outcome depends on the nature of that participation and the degree of willingness to question previously unexamined beliefs and assumptions and to experiment with new behaviors.

In terms of the theory on which CTSP is based, interventions work in so far as they alter the underlying cognitive and behavioral processes that maintain self-consciousness. Vumile's story shows that a critical factor can easily be missed and illustrates how significant change can 
depend on identifying and targeting quite specific processes that may not be adequately addressed even in a program employing a wide range of interventions that are of proven value.

Traditionally, from a behavioral perspective, exposure is the most important intervention in social phobia because it allows conditioned anxiety to habituate. However, for cognitive theorists, exposure is only effective if it modifies the cognitive processes and structures that maintain the phobia. Vumile's case provides strong evidence for this claim. The effect of exposure was linked to the manner in which Vumile processed the evidence obtained from the experience. On occasion, exposure exercises discouraged him, and strengthened his belief that he was different from other people and could never change.

Despite a great deal of exposure and practice, the internalized images of being ridiculed continued to control Vumile's behavior. His personal investigation of women's facial expressions in natural settings was not really an exposure exercise, as he did not interact with them. However, it had a profound impact in terms of restructuring his distorted cognitions and worked in a similar manner to Danger Ideation and Reduction Therapy (DIRT), another nonexposure intervention, developed for OCD clients with washing compulsions (Krochmalik, Jones, and Menzies, 2001). Exposure and response prevention have long been considered fundamental to the treatment of OCD, where, it has been argued, exposure elicits the anxiety and response prevention allows the anxiety to habituate. It has also been hypothesized that the factors giving rise to anxiety are encoded in non-verbal cognitive structures that cannot be altered by means of rational evaluation. In the DIRT treatment clients undertake intensive research into the mechanisms by which infections can be passed from one person to another. This task introduces them to new information that challenges the beliefs that help to maintain their washing compulsions, and there is apparently no need to elicit the intense anxiety normally associated with response prevention. Even without exposure treatment, DIRT has been shown to be highly effective in reducing OCD symptoms in treatment-resistant cases.

It has been argued that social phobics lack social skills so that training in social skills enhances confidence and overcomes the problem. Clark and Wells reject this argument (without implying that skills deficits might not compound the problem in some cases). They point out that since social phobics need to learn to engage spontaneously and unreflectively in the moment-to-moment flux of interaction, a focus on the exercise of skills (including particular interactional moves as well as relaxation techniques) can sometimes interfere with spontaneity and even become a safety behavior in its own right. Vumile's experience supports Clark and Wells. There was, of course, some limited skills training that occurred indirectly and during the role-play in session 8 . In addition, the video feedback intervention is similar to what is included in some social skills training. However this was not followed by formal coaching or skill rehearsal, and the CTSP program did not include explicit skills training. While work on such skills might be appropriate in some cases, the evidence is that Vumile did not need this. When he did start to interact spontaneously, he was not lost for words and was actually witty and entertaining at times. Future research could investigate whether the presence of "latent" social skills could be assessed at the beginning of therapy, as a means of identifying clients without them who might profit from specific social skills training. 
As the program unfolded, Vumile was repeatedly and effectively confronted with insights into the inaccuracy of many of his beliefs and the counter-productive nature of his safety behaviors. Nevertheless, a significant maintaining factor, his internalized images of women ridiculing him, was only identified properly at the end of treatment. This, and the prescription of homework to address it, was a turning point. It seems improbable that Vumile would have made the rapid progress he did after the program was formally over had this not come to light. This shows the importance of the principle, central to the individualized case formulation approach to cognitive therapy, that the idiosyncratic processes of the particular case need to be identified and addressed (Tomkins, 1997; Persons and Tomkins, 1997).

Hilliard (1993) points out that case study research builds knowledge not by aggregation of scores into a mean which is compared with that of a control condition, but by clinical replication in which the processes in response to an intervention are examined in depth so that the researchers can observe whether they are similar to what was observed in previously reported cases. Edwards, Dattilio, and Bromley (2004) also discuss how, with a case-based research methodology, clinical replications not only serve to confirm existing theory, but also to elaborate and refine it. In the present study, Vumile's response to the various components of the Clark and Wells intervention were similar to those described by Clark and Wells themselves. Clark and Wells' model served as a framework within which the group leaders helped Vumile identify the factors maintaining his social phobia and to alter them by means of several specific therapeutic strategies. The narrative provides evidence that Vumile's anxiety symptoms were related to an automatic focusing on negative images of himself, which were then associated with negative thoughts and predictions about the outcome of social interactions. In turn, the self-protective safety behaviors automatically mobilized to reduce the perceived threat had the perverse effect of making the situation worse.

All this could easily be mapped into Clark and Wells' general framework (Figure 1). Furthermore, the interventions recommended by Clark and Wells were found to be effective in building Vumile's awareness of the self-defeating cycles in which he was trapped, and in providing him with the means to challenge dysfunctional beliefs and attitudes and to discover an alternative and self-enhancing way of interacting socially. The present study thus provides a successful clinical replication of the work of Clark and Wells. This adds to the empirical support for the Clark and Wells model as well as for its general utility since, although the authors had Clark's support, they received no training or supervision from anyone involved in the development or implementation of the model and worked at a site in South Africa where this approach is largely unknown.

The study also extends the work of Clark and Wells by showing that a group version of the treatment (albeit with an intensive, individual, Safety Behaviors Experiment session included) can combine the advantages of individual and group treatment. Vumile participated in all the activities and exercises specified in the manual. By spending five sessions on the development of each participant's model, the therapists could get to know each individual's specific cognitive and behavioral patterns. This was facilitated by the small number of 
participants, by having participants hand in reports on homework at the beginning of sessions so that the group leader (the first author) could familiarize himself with each case while his assistants started the group, and by photocopying homework and in-session exercises so that we could track participants in some detail. This case study provides evidence that these strategies enabled us to approximate the conditions of individual therapy in terms of information-gathering and case formulation. Further research will be needed to establish whether this approach would improve on the rather low effect size of group treatment relative to individual treatment reported by Stangier et al. (2003).

The case narrative also shows that there were a number of advantages to being involved in a group program. First, Vumile could identify with other group members in terms of their shared problem (Yalom, 1995). Second, members provided each other with social support within and outside the group. Third, the group provided a forum for learning to trust others and to experience meaningful interpersonal interactions. Fourth, group members provided Vumile with honest and accurate feedback on his behavior both within and outside of the group. For example, it was Lindiwe's feedback about responses to Vumile in the residence hall that played a key role in bringing to light the imagery process contributing to the maintenance of his experience of being ridiculed by women.

Another motivating factor that the Clark and Wells psycho-educational model provided was a credible framework within which Vumile was able to relate, learn, and put to practical use a set of everyday tools for dealing with challenging social situations. He engaged with the program thoughtfully and intelligently, and he developed a sound working understanding of the cognitive model. In particular the concept of "safety behaviors" was of considerable practical use to him. He came to understand how they interfered with spontaneity and thus raised his anxiety, and he regularly used the phrase in giving himself self-instructions to drop them, as examples from the case narrative show. Further, Vumile fully understood the significance of collecting evidence from ongoing data as a means of correcting cognitive distortions, since his observational exercise of watching women's facial expressions after the program was over was largely pursued on his own initiative. Additional motivation was provided by the presence of other group members. They provided meaningful social support in and outside the group. Vumile was challenged by other group members' experiences in response to the various components of the program, and, though discouraged at times because be perceived himself as falling behind, he also felt competitive and was motivated to prove himself by taking on difficult homework exercises.

The study also raises the question of how the initial assessment model might be modified in a way that might have brought to light earlier the role of Vumile's internally generated images. The model recognizes the role of images in the "Self-Focus" component (Figure 1, Box 3 ), but there is less emphasis on this in the "Threat-Related Thoughts" component of Box 2. This component includes a diversity of cognitive processes and contents, including cognitive biases and distortions about other people in interpersonal situations. Rapee and Heimberg's (1997) analysis of social phobia, which has many commonalities with that of Clark and Wells 
(Wilson \& Rapee, 2003), includes a component referred to as "perceived audience." That is, the model emphasizes the fact that the social phobic responds not to the actual behavior of an actual audience, but to "any other person or group of people who may potentially perceive an individual's appearance or behavior" (p. 744) and respond with negative evaluation. The general nature of the expected negative evaluation is covered by the "Threat-Related Thoughts" Box in Figure 1. However, the important mechanism in Vumile's case is incompletely characterized by phrases such as "distorted belief" or "cognitive bias" (e.g., McManus, Clark, \& Hackmann, 2000), which refer to errors of belief or judgement rather than distortions of perception.

Hackmann, Clark, \& McManus (2000) have shown that early memories of aversive social events in which individuals were bullied, mocked, or teased play a role in maintaining cognitive distortions in the present. They focus on the legacy of such memories in terms of "a negative, observer-perspective image of their social selves that is repeatedly activated" (p. 607). However, they do not take up the possibility that it might serve to generate inaccurate images of the other.

In Vumile's case, it was not merely that he believed that women were looking at him with pity and ridicule. He was projecting internally generated images of ridiculing expressions on to everyday real women. Despite accumulating evidence that many women did not ridicule him, he still experienced them as ridiculing him because he seemed to gain fresh evidence for this whenever he was in their company. It is not just that Vumile made an anticipatory prediction that he would be ridiculed. He was seeing the ridicule even though it was not there, and, as it turned out, he was not actually looking at their faces anyway. Although there were hints that this was happening, the exact nature of this subtle process did not come to light until the last session. Yet targeting it proved to be critical for change. This mechanism clearly deserves more research attention, and it may be that the observational exercise that Vumile undertook in the weeks after treatment had ended could be valuable in other cases where this mechanism plays a role in maintaining the phobia.

\section{REFERENCES}

American Psychiatric Association (1980). DSM-III. Diagnostic and statistical manual of mental disorders $\left(3^{\text {rd }}\right.$ ed.). Washington, DC: Author.

American Psychiatric Association (2000). DSM-IV-TR. Diagnostic and statistical manual of mental disorders $\left(4^{\text {th }}\right.$ ed., Text Revision). Washington, DC: Author.

Barker, C., Pistrang, N., \& Elliot, R. (1994). Research methods in clinical and counselling psychology. Chichester: Wiley.

Bates, A. \& Clark, D. (1998). A new cognitive treatment for social phobia: A single case study. Journal of Cognitive Psychotherapy, 12, 289-302.

Beck, A. T. \& Steer, R. A. (1993). Beck Anxiety Inventory Manual. San Antonio TX: Psychological Corporation.

Beck, A. T., Steer, R. A., \& Brown, G. K. (1996). Beck Depression Inventory-II Manual. San Antonio TX: Psychological Corporation.

Buss, A. H. (1980). Self-consciousness and social anxiety. San Francisco: W. H. Freeman.

Clark, D, M. (1997). Cognitive therapy for social phobia: Some notes for therapists. Oxford: University of Oxford, Department of Psychiatry. 
in Group Therapy for Social Phobia: The Case of Vumile

D.J.A. Edwards \& S. Kannan

Pragmatic Case Studies in Psychotherapy, http://pcsp.libraries.rutgers.edu

Volume 2, Module 1, Article 1, pp. 1-30, 02-17-06 [copyright by authors]

Clark, D. M., Ehlers, A., McManus, F., Hackmann, A., Fennell, M., et al. (2003). Cognitive therapy versus Fluoxetine in generalized social phobia: a randomized placebo-controlled trial. Journal of Consulting and Clinical Psychology, 71, 1058-1067.

Clark, D. M. \& Wells, A.(1995). A cognitive model of social phobia. In R. M. Heimberg, M. Leibowitz, D. Hope, \& F. Schneier (Eds.), Social phobia: Diagnosis, assessment and treatment (pp. 69-93). New York: Guilford.

Edwards. D. J. A. (1996). Case study research: The cornerstone of theory and practice. In M. Reinecke, F. M. Dattilio, \& A. Freeman (Eds.) Cognitive therapy with children and adolescents: A casebook for clinical practice (pp. 10-37). New York: Guilford.

Edwards, D. J. A., Dattilio, F. M., \& Bromley, D. B. (2004). Developing evidence-based practice: The role of case-based research. Professional Psychology: Research and Practice, 35, 589-597.

Edwards, D. J. A., Henwood, J., \& Kannan, S. (2003). Cognitive therapy for social phobia: The human face of cognitive science. Alternation, 10 (2), 122-150.

Edwards, D. J. A. \& Kannan, S. (2006). APPENDICES FOR Identifying and targeting idiosyncratic cognitive processes in group therapy for social phobia: The case of Vumile. Pragmatic Case Studies in Psychotherapy [Online], Vol. 2(1), Article 2. Available: http://hdl.rutgers.edu/1782.1/pcsp_journal

Fenigstein, A., Schneier, M. F., \& Buss, A. H. (1975). Public and private self-consciousness: Assessment and theory. Journal of Consulting and Clinical Psychology, 43, 522-527.

Freeman, A., Pretzer, J., Fleming, B., \& Simon, K. M. (1990). Clinical applications of cognitive therapy. New York: Plenum.

Hackmann, A., Clark, D. M., \& McManus, F. (2000). Recurrent images and early memories of social phobia. Behavior Research and Therapy, 38, 601-610.

Heimberg, R. G., \& Juster, H. R. (1995). Cognitive-behavioral treatments: Literature review. In R. G. Heimberg, M. R. Leibowitz, D. A. Hope, \& F. R. Schneier (eds.), Social phobia, diagnosis, assessment and treatment (pp. 261-309). New York: Guilford.

Hilliard, R. B. (1993). Single-case methodology in psychotherapy process and outcome research. Journal of Consulting and Clinical Psychology, 61, 373-380.

Kannan, S. (2002). An adaptation of the Clark (1997) treatment for social phobia into a group therapy format and a preliminary evaluation. Unpublished Master's thesis. Rhodes University, Grahamstown, South Africa.

Krochmalik, A., Jones, M. K., \& Menzies, R. G. ( 2001). Danger ideation reduction therapy (DIRT) for treatment-resistant compulsive washing. Behavior Research and Therapy, 39, 897-912.

Lange, A. J., \& Jakubowski, P. (1976). Responsible assertive behavior. Champaign, IL: Research Press.

McManus, F., Clark, D. M., \& Hackmann, A. (2000). Specificity of cognitive biases in social phobia. Behavioral and Cognitive Psychotherapy, 28, 201-209.

Persons, J. B., \& Tomkins, M. A. (1997). Cognitive-behavioral case formulation. In T. D. Eells (Ed.), Handbook of psychotherapy case formulation (pp. 314-339). New York: Guilford.

Rapee, R. M., \& Heimberg, R. G. (1997). A cognitive-behavioral model of anxiety in social phobia. Behavior Research and Therapy, 35, 741-756. 
Sank, L. L. \& Shaffer, C. S. (1984). A therapist's manual for cognitive behavior therapy in groups. New York: Plenum.

Stangier, U., Heidenreich, T., Peitz, M., Lauterbach, W., \& Clark, D. M. (2003). Cognitive therapy for social phobia: Individual versus group treatment. Behavior Research and Therapy, 41, 991-1007.

Tomkins, M. A. (1997). Case formulation. In R. L. Leahy (Ed.), Practising cognitive therapy: A guide to interventions (pp. 37-59). Northvale, NJ: Jason Aronson.

Wells, A. (1997). Cognitive therapy of anxiety disorders: A practice manual and conceptual guide. Chichester: Wiley.

Wells, A., \& Clark, D. M. (1997). Social phobia: A cognitive approach. In G. C. L. Davey (Ed.), Phobias: A handbook of theory, research and treatment (pp. 3-26). New York: Wiley.

Wells, A, \& Papageorgiou, C. (1997). Brief cognitive therapy for social phobia: A case series. Behavior Research and Therapy, 39, 713-720.

White, J. R. \& Freeman, A. (2000). Cognitive-behavioral group therapy for specific problems and populations. Washington DC: American Psychological Association.

Wilson, J. K., \& Rapee, R. M. (2003). Cognitive theory and therapy of social phobia. In M. A. Reinecke, \& D. A. Clark (Eds)., Cognitive therapy across the lifespan (pp. 258-292). Cambridge: Cambridge University Press.

Yalom, I. (1995). The theory and practice of group psychotherapy $\left(4^{\text {th }} \mathrm{ed}\right.$.). New York: Basic Books. 
in Group Therapy for Social Phobia: The Case of Vumile

D.J.A. Edwards \& S. Kannan

Pragmatic Case Studies in Psychotherapy, http://pcsp.libraries.rutgers.edu

Volume 2, Module 1, Article 1, pp. 1-30, 02-17-06 [copyright by authors]

Table 1. Ratings Made After Each Role-Play of the SBE

\begin{tabular}{|l|l|c|c|}
\hline \multicolumn{2}{|l|}{ Max score 10 indicates a high degree of anxiety or } & Vumile & Volunteer \\
\multirow{2}{*}{ self-consciousness and a good level of } & & \\
performance & Vumile's anxiety & 9 & 5 \\
\hline \multirow{3}{*}{ First } & Vumile's self-consciousness & 9 & 6 \\
\cline { 2 - 4 } role-play & Vumile's overall performance & 3 & 7 \\
\cline { 2 - 4 } & Vumile's anxiety & 5 & 2 \\
\cline { 2 - 4 } Second & Vumile's self-consciousness: & 3 & \\
\cline { 2 - 4 } role-play & Vumile's overall performance & 6 & \\
\cline { 2 - 4 } & & & \\
\hline
\end{tabular}




\section{Figure 1}

\section{Vumile's social phobia in terms of the Clark and Wells model}

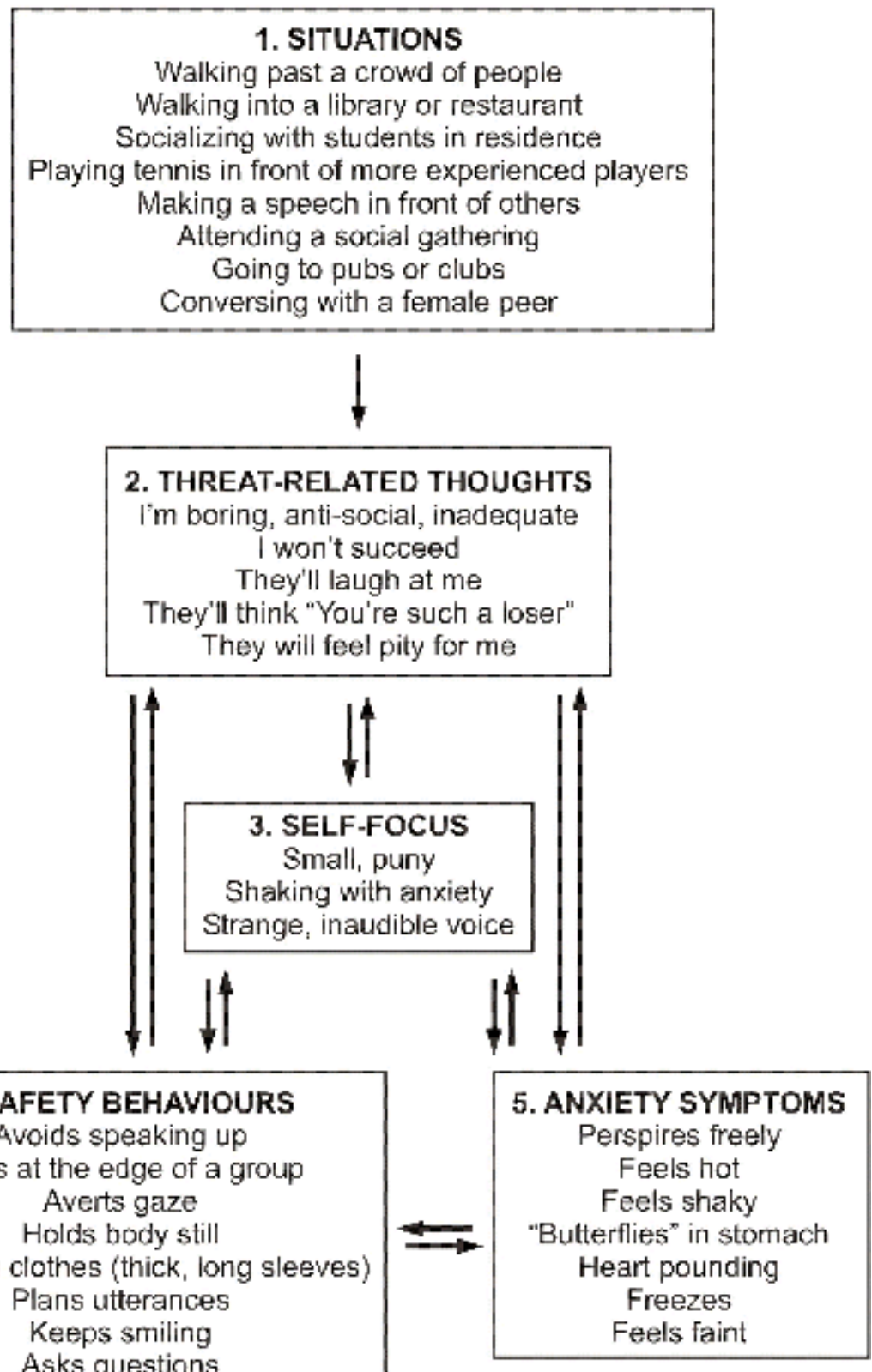

4. SAFETY BEHAVIOURS

Avoids speaking up

Stays at the edge of a group

Averts gaze

Wears full clothes (thick, long sleeves)

Keeps smiling

Asks questions
5. ANXIETY SYMPTOMS erspires freely

Feels hot

Feels 
in Group Therapy for Social Phobia: The Case of Vumile

D.J.A. Edwards \& S. Kannan

Pragmatic Case Studies in Psychotherapy, http://pcsp.libraries.rutgers.edu

Volume 2, Module 1, Article 1, pp. 1-30, 02-17-06 [copyright by authors]

FIGURE2

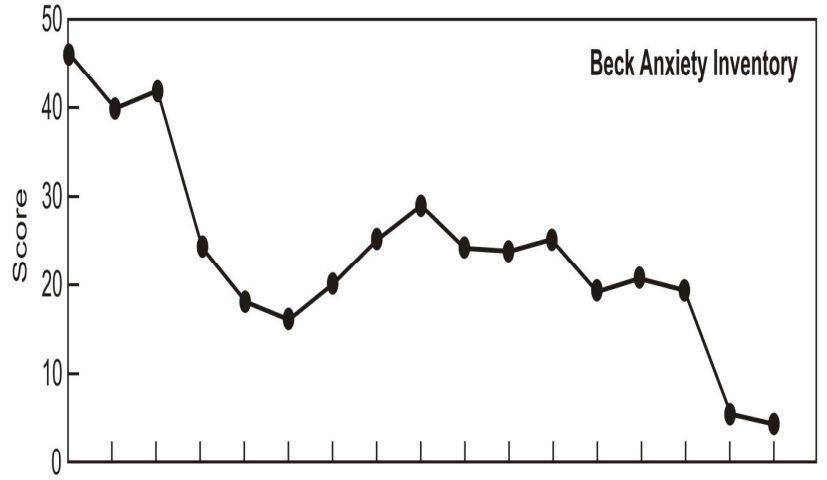

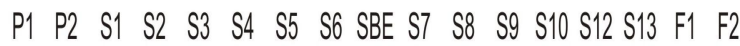

\section{FIGURE 4}

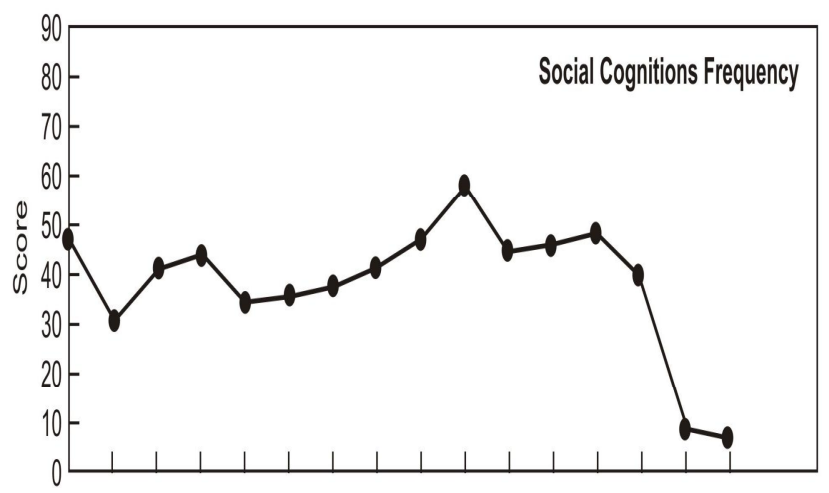

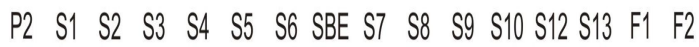

FIGURE 3

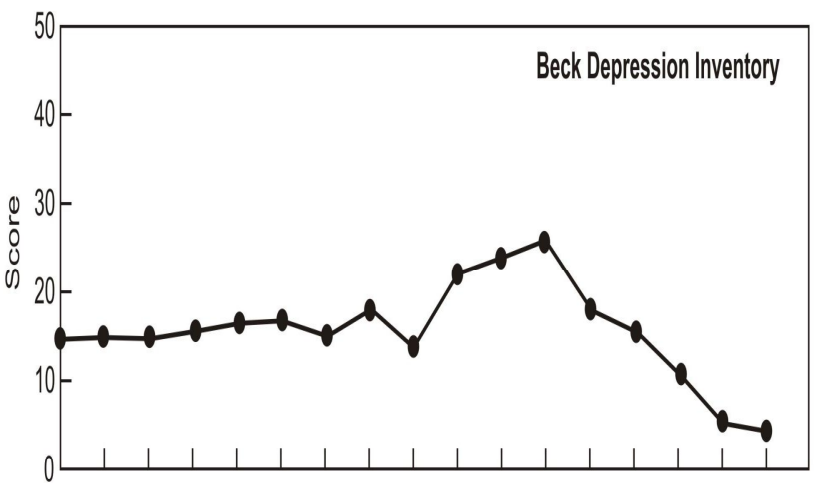

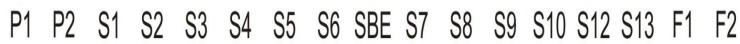
FIGURE 5

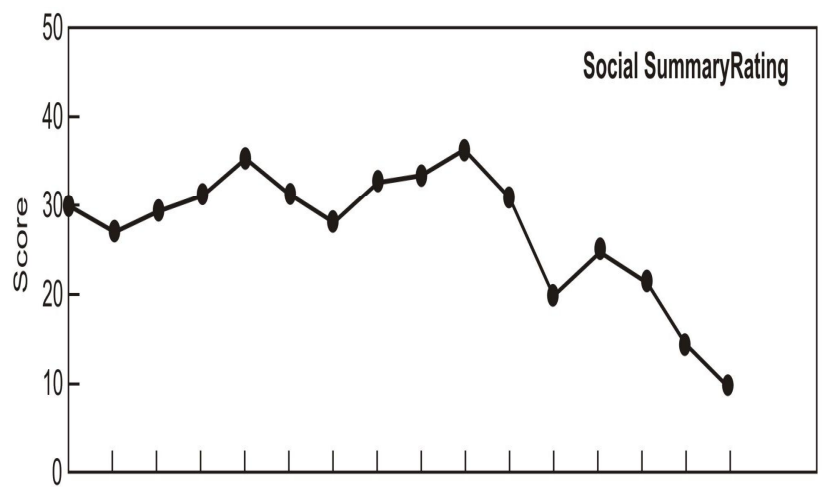

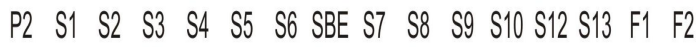

\section{FIGURE 6}

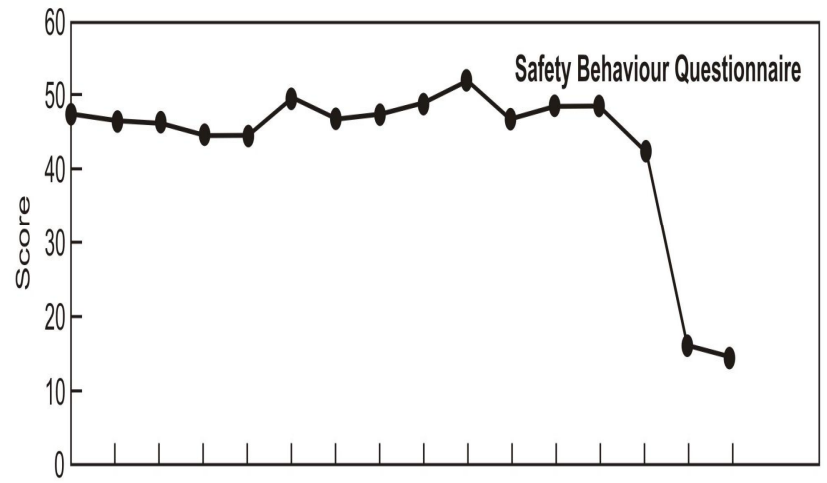

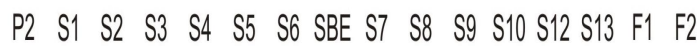

